\title{
Influence of the Glycemic Index of Pre-exercise Meals in Sports Performance: A Systematic Review
}

\author{
Laura Camargo Ferrugem¹, Gabriela Lucciana Martini ${ }^{2}$, Carolina Guerini de Souza ${ }^{2,3,4 *}$ \\ ${ }^{1}$ Postgraduate Program in Health Sciences (PPGCS), Universidade Federal de Ciências da Saúde de Porto Alegre (UFCSPA), Porto \\ Alegre, Rio Grande do Sul, Brazil \\ ${ }^{2}$ Postgraduate Program in Food, Nutrition and Health (PPGANS), Universidade Federal do Rio Grande do Sul (UFRGS), Porto Alegre, \\ Rio Grande do Sul, Brazil \\ ${ }^{3}$ Departament of Nutrition, Universidade Federal do Rio Grande do Sul (UFRGS), Porto Alegre, Rio Grande do Sul, Brazil \\ ${ }^{4}$ Nutrition and Dietetics Service, Hospital de Clínicas de Porto Alegre (HCPA), Porto Alegre, Rio Grande do Sul, Brazil
}

Corresponding Author: Carolina Guerini de Souza, Professor, Postgraduate Program in Food, Nutrition and Health (PPGANS), Universidade Federal do Rio Grande do Su, Rua Ramiro Barcelos 2400, $2^{\circ}$ andar, Santa Cecília, Porto Alegre, Rio Grande do Sul, Brazil. Tel: +55-513308-5509, Fax: +55-513308-5232, Email: carolina.guerini@ufrgs.br

Received November 7, 2018; Accepted December 13, 2018; Online Published December 27, 2018

\begin{abstract}
Introduction: Carbohydrate $(\mathrm{CHO})$ is essential for physical exercise. Some strategies for improving performance are based on the manipulation of the glycemic index (Gl) of this nutrient during pre-exercise. Although several studies have been conducted on this subject, the use of low or high $\mathrm{Gl}$ in a pre-exercise meal to improve performance remains undefined.

Methods: In the present systematic review, the Pubmed (Medline) and Virtual Health Library databases were searched for randomized clinical trials conducted with healthy, physically active adults between 2006 and 2019, in which performance in addition to blood biochemical parameters, substrate utilization, body composition, perception of effort, and gastrointestinal symptoms were evaluated. The identified articles were independently and blindly evaluated by two authors, and any disagreements were resolved by a third investigator. Results: Five of the sixteen studies reviewed found differences in performance; of these, four were with low Gl intervention. Few studies showed modifications in blood lactate and glucose levels beyond fatty free acid oxidation. No differences could be seen in the other parameters. The results as well as the methodologies used were heterogeneous; therefore, there are no clear advantages in determining the specific Gl of the pre-exercise meal.

Conclusions: There is no evidence that the pre-exercise meal Gl influences performance. The heterogeneity of the studies precludes further conclusions.

Keywords: Glycemic index, Exercise, Athletic Performance

Citation: Ferrugem LC, Martini GL, de Souza CG. Influence of the glycemic index of pre-exercise meals in sports performance: a systematic review. Int J Med Rev. 2018;5(4):151-158. doi:10.29252/JMR-050405.
\end{abstract}

\section{Introduction}

The carbohydrate $(\mathrm{CHO})$ is an essential nutrient for physical exercise because of its versatile substrate role in muscle work. In addition to maintaining glycemia and the energy supply to the brain, it is capable of contributing to exercises of various intensities due to its use in anaerobic and aerobic passages. ${ }^{1}$ Because of this, different amounts and types of $\mathrm{CHOs}$ are required to achieve different effects during exercise., ${ }^{2,3}$

Some strategies for improving sports performance are based on the characteristics of $\mathrm{CHO}$ and its glycemic index (GI), which have been extensively studied in order to investigate what influence they may have, especially in the pre-exercise meal. Previous studies have shown that the course of plasma glucose and insulin levels, following the ingestion of low GI $\mathrm{CHO}$, favors the increase of free fatty acids (FFA), fat oxidation, and blood glucose homeostasis during exercise. ${ }^{4-6}$ In contrast, high GI meals in pre-exercise seem to decrease fat oxidation and increase the release of hormones that stimulate glycogen breakdown..$^{7-9}$ Decreased muscle glycogen levels are associated with fatigue and reduced intensity of sustained exercise, and thus impair factors that influence performance, such as stimulation, the perception of fatigue, motor ability, and concentration. This fact instigates the constant concern with the adequate supply of $\mathrm{CHO}$, fundamental to maintaining its ergogenic effect, necessary in all sports activities at all levels, but mostly in those of high intensity and long duration. ${ }^{1,10,11}$ However, the results of the studies in relation to the sports performance still remain disparate.

Despite the aforementioned biochemical assumptions, studies comparing the effect of pre-exercise meals with low GI vs. high GI content on exercise performance have produced conflicting results, and several critics have reported that the evidence is inconclusive. ${ }^{12,13}$ Therefore, this study aimed to evaluate the impact of pre-exercise meal GI on performance

Copyright $\odot 2018$ The Author(s). This is an open-access article distributed under the terms of the Creative Commons Attribution License (http:// creativecommons.org/licenses/by/4.0), which permits unrestricted use, distribution, and reproduction in any medium, provided the original work is properly cited. 
improvement in healthy individuals through a systematic review.

\section{Methods}

The current systematic review was performed using a pre-determined protocol established according to the recommendations of the Cochrane Handbook, ${ }^{14}$ and the results were presented according to the criteria of the Preferred Reporting Items for Systematic Reviews and MetaAnalyses (PRISMA Statement). ${ }^{15}$ Randomized clinical trials (RCTs) published in English from 2006 that investigated the possible effects of a meal's GI on exercise performance in adults of both sexes were reviewed, and it was determined that interventions were always carried out on physically active and healthy individuals. In January 2019, a search of the Medline (via PubMed) and Virtual Health Library (VHL) electronic databases was performed for the descriptors "Glycemic Index and Exercise" and "Glycemic Index and Sports" in research titles or abstracts. Biochemical, physical, and clinical parameters evaluated in each study's participants were considered as outcomes of interest as long as they were associated with performance (time to complete the exercise, traveled distance, or exercise to exhaustion) and the preexercise meal was offered 30 minutes to 4 hours before exercise was begun. No evaluations and/or changes in participants prior to physical exercise were considered as outcomes of interest. Similarly, performed and unpublished studies, abstracts of scientific events (published or unpublished), dissertations, and these were not included. The identified articles were independently and blindly evaluated by two authors of the present manuscript (LCF and GLM), and any disagreement regarding the inclusion of a study was resolved by a third investigator (CGS).

\section{Results}

Using the aforementioned descriptors and filters, 16 articles were selected as shown in the flowchart depicted in Figure 1.

The impact factor of the selected publications ranged from 1.11 to 3.76 , and a large number of them was above 2.0 (46\%). The year of publication ranged from 2006 to 2019, with most studies published in 2009, and the sample mean was 9.8 \pm 3.6 individuals. The interventions were low and/or high GI meals, and the amount of $\mathrm{CHO}$ ranged from $1 \mathrm{~g}$ to $10 \mathrm{~g} / \mathrm{kg}$ of body weight, with most studies using 1-2 g CHO/kg, ingested between 45 minutes and 4 hours before exercise. The physical modalities studied were cycling (50\%), running (25\%), and soccer simulation (25\%). The results, grouped according to their main outcomes, are summarized in Table 1. The differences between all the intervention groups (high GI, low GI, and control/placebo) are described in the table; however, only the differences between high and low GI are described in the following items.

\section{Performance}

The performance evaluations of the studies included in this review adopted the variables time to complete the exercise, time to exhaustion, distance, power or number of sprints, in
$75.2 \pm 8.1$ minutes, $P<0.05)$.

In the four studies that obtained advantageous results regarding performance in the low GI group, the amount of CHO used was between $1-2.5 \mathrm{~g} / \mathrm{kg}$ of weight. ${ }^{16,17,19,20}$ These effects were obtained by consuming mostly planned meals with low GI foods, such as bran and cereal flakes, skimmed and semi-skimmed milk, apple, peach, apple juice and water, from 45 minutes to 3 hours before exercise.

In the study that found performance advantages in the high GI group, ${ }^{18}$ it was verified that the amount of $\mathrm{CHO}$ used was of $1.5 \mathrm{~g} / \mathrm{kg}$, being a planned meal with high GI foods, such as potato, tomato sauce, white bread, processed cheese, and watermelon.

\section{Biochemical Parameters}

All 16 selected studies evaluated one of the following biochemical parameters: glycemia, insulinemia, glycerol, FFA, triglycerides (TG), hemoglobin ( $\mathrm{Hb})$, hematocrit (Ht), LACTATE, cortisol, sodium, potassium, osmolarity, interleukins (ILs), TNF-alpha (TNF- $\alpha$ ), $\beta$-hydroxybutyrate (BHB), or blood $\beta$-endorphin before, during, or after exercise. Glycemia was the only parameter evaluated in all the

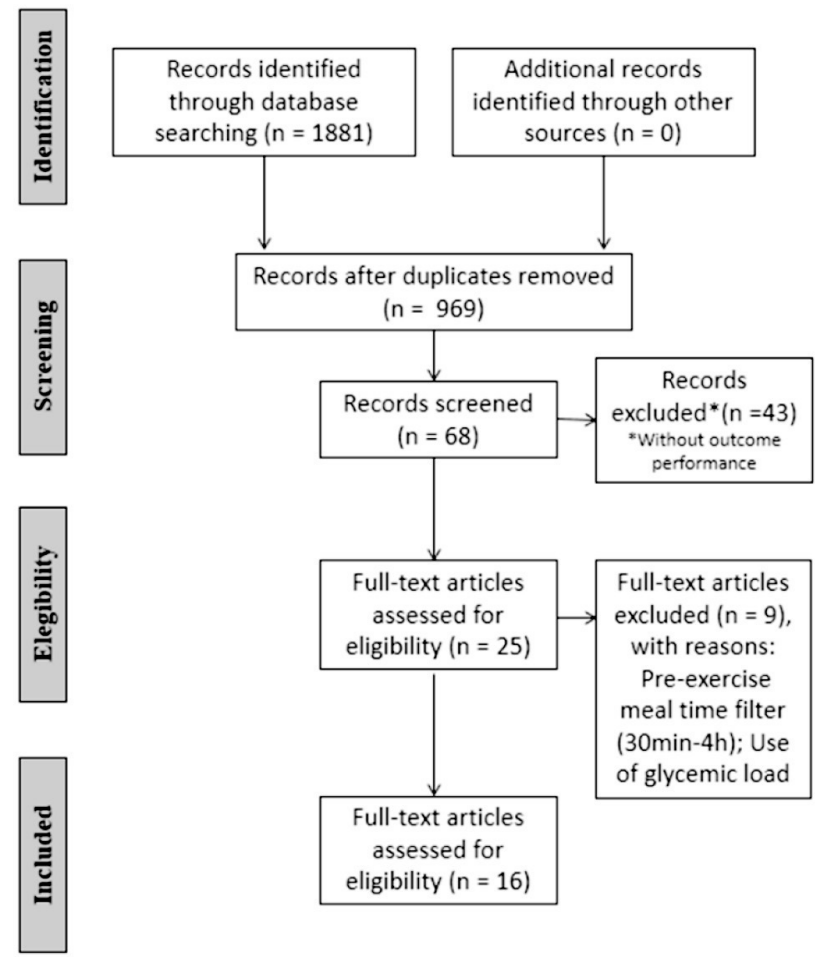

Figure 1. Flowchart of Studies Selection.

order to measure this parameter. However, only five found significant results. ${ }^{16-20}$

Two studies measured time to complete the test ${ }^{17,19}$ and the use of low GI-favored performance in these studies (high $\mathrm{x}$ low GI: $95.6 \pm 6.0$ minutes $x$ 92.5 \pm 5.2 minutes; $96 \pm 7$ minutes x $93 \pm 8$ minutes; $31.08 \pm 6.27$ minutes x $30.05 \pm 4.7$ minutes., $P<0.05$, respectively). This same advantage can be observed in 2 other studies ${ }^{16,20}$ which evaluated time to exhaustion, 
Table 1. Influence of Pre-exercise Meals Glycemic Index on Evaluated Outcomes

\begin{tabular}{|c|c|c|c|c|}
\hline Authors & $\begin{array}{l}\text { Type of Study and } \\
\text { Population }\end{array}$ & Intervention & Outcomes & Conclusions \\
\hline $\begin{array}{l}\text { Wu \& } \\
\text { Williams } \\
(2006)^{16}\end{array}$ & $\begin{array}{l}\text { RCT crossed with } \\
\text { runners of the male } \\
\text { sex }(n=8)\end{array}$ & $\begin{array}{l}\text { Low or high Gl meals providing } \\
2 \mathrm{~g} / \mathrm{kg} \text { of } \mathrm{CHO}, 3 \text { hours before } \\
\text { exercise (run to exhaustion). Trials } \\
\text { with } 7 \text {-day intervals. }\end{array}$ & $\begin{array}{l}\text { Glucose, insulin, lactate, FFA, } \\
\text { glycerol, } \mathrm{Ht}, \mathrm{Hb} \text {; fat oxidation } \\
\text { and } \mathrm{CHO} \text {; energy expenditure; } \\
\mathrm{RER} \mathrm{VO}_{2}, \mathrm{VCO}_{2} \text {; perceptions of } \\
\text { effort and thirst, fullness; body } \\
\text { mass; fatigue; performance } \\
\text { (running time) }\end{array}$ & $\begin{array}{l}\text { The low GI group obtained higher glycemia in the first } \\
30 \text { minutes of exercise; however, there was no difference } \\
\text { between the two groups after the first } 30 \text { minutes of } \\
\text { running; } \\
\text { RER values were higher during the first } 90 \text { minutes of } \\
\text { running in the high Gl group; } \\
\text { FFA and glycerol concentrations were significantly } \\
\text { higher in the low Gl group during all exercises, } \\
\text { accompanied by a higher rate of fat oxidation. Fatigue } \\
\text { was also higher in this group; } \\
\text { The average time to exhaustion was significantly higher } \\
\text { in the low Gl group. According to protocol (walking for } \\
2 \text { minutes when fatigue was reported for the first time), } \\
\text { the duration of the running exercise at this point was also } \\
\text { significantly higher in the low Gl group; } \\
\text { In the other variables, no significant difference was } \\
\text { found. }\end{array}$ \\
\hline
\end{tabular}

Moore et at Blind RCT crossed with cyclists of the male sex $(n=8)$

Low or high Gl meal, providing $1 \mathrm{~g} / \mathrm{kg}$ of $\mathrm{CHO} 45$ minutes before exercise $(40 \mathrm{~km}$ in cycle ergometer. Two trials were performed with 7-day intervals.

Low or high GI meals, providing $1.5 \mathrm{~g}$ of $\mathrm{CHO} / \mathrm{kg}$ at a recovery time of 4 hours, after a constant

Wong et al Blind RCT crossed

with physically active individuals of 90-minute run, followed by runnin the male sex $(n=7)$
Glucose; lactate, osmolarity; fat oxidation and $\mathrm{CHO}$; RER $\mathrm{VO}_{2}, \mathrm{VCO}_{2}$; perception of effort; performance (time to travel 40 $\mathrm{km})$.

The low Gl group presented higher glycemia at the end of the exercise and also a better performance compared to the high Gl group.

In the other variables, no significant difference was found.

Glucose, insulin, lactate, FFA, glycerol, cortisol, $\mathrm{Ht}$ $\mathrm{Hb}$, sodium, potassium and osmolarity; fat oxidation and $\mathrm{CHO} ; \mathrm{RER}, \mathrm{VO}_{2}$; perception of effort and thirst, abdominal discomfort; body mass; performance (running time)

Glucose, insulin, lactate, FFA, TG and plasma osmolarity; fat oxidation and $\mathrm{CHO}$; $\mathrm{RER}$; $\mathrm{VO}_{2}$ $\mathrm{VCO}_{2}$; perception of effort; performance (cycling time)

Glucose and lactate; $\mathrm{VO}_{2}$; body mass; performance (cycling time and distance).

Glucose, lactate; fat oxidation and $\mathrm{CHO}$; energy expenditure $\mathrm{RER}, \mathrm{VO}_{2}, \mathrm{VCO}_{2}$; power in the final 5 minutes of performance (cycling time).

At the time of exhaustion, plasma concentrations of FFA and glycerol were higher in the high GI group; The time to exhaustion was lower after low Gl meals in the recovery period, indicating a better performance in the high Gl group

In the other variables, no significant difference was found.

RER significantly higher in the low Gl group;

Average time of exercise and fat oxidation was significantly lower in the low Gl group;

In the other variables, no significant difference was found.

The time of cycling to exhaustion was higher in the low Gl group, the same as the lactate levels were lower during exercise;

In the other variables, no significant difference was found.

Athletes who ingested palatinose had greater power in the final 5 minutes of exercise, in addition to highe glycemia and higher fat oxidation during the test. There was a likely benefit, from small to moderate, in the time to complete the test after the ingestion of this beverage;

In the other variables, no significant difference was found.

Glycemia was higher at the end of the second exercise session in the low $\mathrm{Gl}$ group;

Lactate in the blood was higher near the end of the

Double-blind RCT and crossed with Bennett et individuals of the al (2012) 22 male $(\mathrm{n}=10)$ and female sex $(n=4)$ amateur soccer players.
Low or high $\mathrm{Gl}$ meal, $2 \mathrm{~h}$ before $(1.5 \mathrm{~g} / \mathrm{kg}$ of $\mathrm{CHO})$ and within $1 \mathrm{~h}$ after the first session of intermittent exercise (90 minutes), being provided $2 \mathrm{~g} / \mathrm{kg}$ of $\mathrm{CHO}$. The sessions were separated by $3 \mathrm{~h}$, with 45 minutes each session. Trial with 7-day intervals.
Glucose, insulin, lactate and FFA; fat oxidation and $\mathrm{CHO}$; RER, $\mathrm{VO}_{2}, \mathrm{VCO}_{2}$; perception of effort, fullness and gastrointestinal symptoms; sprint performance second session of intermittent high intensity exercise in the high GI group

For the last point of time (after sprints at the end of the second exercise session) women of the high GI group presented higher levels of FFA;

$\mathrm{CHO}$ oxidation was higher in the high $\mathrm{Gl}$ group at the beginning of the first exercise session;

In the other variables, no significant difference was found.

Low or high GI meal or control (hypocaloric, fat and sugar free),

RCT crossed with Wong et al runners of the male $(2009)^{23} \quad \operatorname{sex}(n=9)$ providing $1.5 \mathrm{~g} / \mathrm{kg}$ of $\mathrm{CHO} 2$ hours before exercise ( $21 \mathrm{~km}$ of running). Consumption of a solution of $\mathrm{CHO}$ $6.6 \%(2 \mathrm{ml} / \mathrm{kg})$ immediately before and during exercise. Trials with 7-day intervals.
Glucose, insulin, lactate, AGL, glycerol, $\mathrm{Ht}, \mathrm{Hb}$, sodium, potassium, osmolarity; fat oxidation and $\mathrm{CHO}$; $\mathrm{RER}, \mathrm{VO}_{2}$ $\mathrm{VCO}$; perception of effort and of thirst, abdominal discomfort, fullness; loss of sweat; performance (running time)
The concentrations of glycerol were higher during exercise in the control group when compared to the high Gl group and also higher at $10 \mathrm{~km}, 15 \mathrm{~km}$ and $21 \mathrm{~km}$ in the control group when compared to the low GI group; In the other variables, no significant difference was found. 
Table 1. Continued

\begin{tabular}{|c|c|c|c|c|}
\hline Authors & $\begin{array}{l}\text { Type of Study and } \\
\text { Population }\end{array}$ & Intervention & Outcomes & Conclusions \\
\hline $\begin{array}{l}\text { Hulton et al } \\
(2012)^{24}\end{array}$ & $\begin{array}{l}\text { RCT crossed with } \\
\text { amateur soccer } \\
\text { players of the male } \\
\text { sex }(n=8)\end{array}$ & $\begin{array}{l}\text { Low or high } \mathrm{Gl} \text { meal providing } \\
2 \mathrm{~g} / \mathrm{kg} \text { of } \mathrm{CHO}, 3.5 \mathrm{~h} \text { before a } \\
\text { traditional soccer game. Trials with } \\
\text { 7-day intervals. }\end{array}$ & $\begin{array}{l}\text { Glucose, insulin, lactate, FFA, } \\
\text { glycerol, BHB; fat oxidation } \\
\text { and } \mathrm{CHO} \text {; perception of effort, } \\
\text { fullness; performance in } 1 \mathrm{~km} \text { of } \\
\text { pre-test (time) }\end{array}$ & $\begin{array}{l}\text { There was no significant difference in the other variables } \\
\text { evaluated. }\end{array}$ \\
\hline $\begin{array}{l}\text { Chen et al } \\
(2009)^{25}\end{array}$ & $\begin{array}{l}\text { RCT with runners of } \\
\text { the male sex }(n=8)\end{array}$ & $\begin{array}{l}\text { Meals of low or high } \mathrm{Gl} \text { ( } 1.5 \mathrm{~g} / \mathrm{kg} \text { of } \\
\mathrm{CHO} \text { ) or control (hypocaloric, fat } \\
\text { and sugar free), } 2 \text { hours before } 21 \\
\mathrm{~km} \text { of running. } \\
\text { Consumption of a solution of } \mathrm{CHO} \\
6.6 \%(2 \mathrm{~mL} / \mathrm{kg}) \text { immediately before } \\
\text { and during exercise. }\end{array}$ & $\begin{array}{l}\text { Glucose, insulin, cortisol, } \mathrm{Ht}, \mathrm{Hb} \text {, } \\
\text { TNF- } \alpha \text {, interleukin-2 (IL-2) and } \\
\text { interleukin- } 6 \text { (IL-6); fat oxidation } \\
\text { and } \mathrm{CHO} \text {; performance (running } \\
\text { time) }\end{array}$ & $\begin{array}{l}\text { Levels of IL- } 6 \text { and cortisol increased after exercise in all } \\
\text { three groups; } \\
\text { The levels of IL-2 decreased in control; } \\
\text { In the other variables, no significant difference was } \\
\text { found. }\end{array}$ \\
\hline
\end{tabular}

\begin{tabular}{|c|c|c|}
\hline $\begin{array}{l}\text { Kern et al } \\
(2007)^{26}\end{array}$ & $\begin{array}{l}\text { Blind RCT crossed } \\
\text { with cyclists of the } \\
\text { male }(n=4) \text { and } \\
\text { female sex }(n=4)\end{array}$ & $\begin{array}{l}\text { Moderate or high Gl meal } \\
\text { providing } 1 \mathrm{~g} / \mathrm{kg} \text { of } \mathrm{CHO}, 45 \\
\text { minutes before exercise (cycling } \\
\text { followed by } 15 \text { minutes of } \\
\text { performance testing). Trials with } \\
\text { 7-day intervals. }\end{array}$ \\
\hline $\begin{array}{l}\text { Little et al } \\
(2009)^{27}\end{array}$ & $\begin{array}{l}\text { Blind RCT crossed } \\
\text { with athletes of the } \\
\text { male sex }(n=7)\end{array}$ & $\begin{array}{l}\text { Low or high } \mathrm{Gl} \text { meal or control } \\
\text { (fasting), providing } 2 \mathrm{~g} / \mathrm{kg} \text { of } \mathrm{CHO} \\
3 \text { hours before exercise ( } 90 \text { minutes } \\
\text { of soccer simulation, separated in } \\
\text { two halves, with } \mathrm{CHO} \text { reposition } \\
-0.25 \mathrm{~g} / \mathrm{kg} \text { - in the interval of } 15 \\
\text { minutes between the two times). } \\
\text { Trials with } 7 \text {-day intervals. }\end{array}$ \\
\hline
\end{tabular}

Glucose, insulin, lactate, FFA, $\mathrm{TG}, \mathrm{Ht}, \mathrm{Hb}, \mathrm{BHB}$; performance (distance traveled in 15 minutes)

There was no significant difference in the variables evaluated.

\begin{tabular}{|c|c|c|c|}
\hline $\begin{array}{l}\text { Little et al } \\
(2010)^{28}\end{array}$ & $\begin{array}{l}\text { Blind RCT crossed } \\
\text { with athletes of the } \\
\text { male sex }(n=16)\end{array}$ & $\begin{array}{l}\text { Fasting (control) or low or high Gl } \\
\text { meal providing } 1.5 \mathrm{~g} / \mathrm{kg} \text { of } \mathrm{CHO} 2 \\
\text { hours before intermittent exercise } \\
\text { ( } 90 \text { minutes of soccer simulation } \\
\text { separated in two halves). Trials with } \\
\text { 7-day intervals. }\end{array}$ & 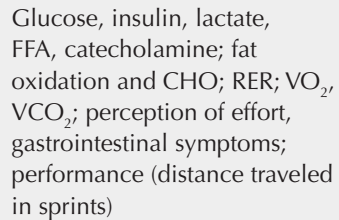 \\
\hline
\end{tabular}

Glucose; fat oxidation and $\mathrm{CHO}$ RER, $\mathrm{VO}_{2}$; perception of effort; performance (distance traveled).
RER was higher and fat oxidation was lower during exercise in the high Gl group when compared to the control group.

In the other variables, no significant difference was found.

The levels of catecholamine were significantly higher at the end of the exercise in the high Gl group when compared to the control group;

Fat oxidation in the low Gl group was significantly lower at the 63-70 minutes of exercise when compared to the control group, the same as fat oxidation in the high Gl group was lower at 33-40 minutes when compared to control;

The perception of effort was significantly lower in the low Gl group when compared to control;

In the other variables, no significant difference was found.

Glucose, insulin, lactate, $\mathrm{Ht}, \mathrm{Hb}$, Although there were some oscillations in glycemia and

beta endorphin; fat oxidation and insulinemia between the groups during exercise, there Fasting (control) or low or high GI $\mathrm{RCT}$ crossed with meal providing $1.5 \mathrm{~g} / \mathrm{kg}$ of $\mathrm{CHO}$ Jamurtas et $\quad$ untrained individuals 30 minutes before exercise (cycling al $(2011)^{29} \begin{aligned} & \text { untrained individuals } \\ & \text { of the male sex }(n=8)\end{aligned}$ intervals. $\mathrm{CHO} ; \mathrm{VO}_{2}, \mathrm{VCO}_{2}$; perception of effort; performance (time to exhaustion) was no significant difference in the variables evaluated at the end of the exercise.

In the other variables, no significant difference was found.

Low or high $\mathrm{Gl}$ meal, providing $8 \mathrm{~g}$ $\mathrm{kg}$ of $\mathrm{CHO}$ over the 24 hours after the glycogen depletion exercise (2 hours of cycling). The next day, after 2-3 h of low or high GI meal, $40 \mathrm{~km}$ of cycling was performed. Trials with 7-day intervals.

Glucose, insulin, lactate, FFA TG, osmolarity; fat oxidation and $\mathrm{CHO}$; energy expenditure; RER; $\mathrm{VO}_{2}, \mathrm{VCO}_{2}$; perception of effort; There was no significant difference in the variables evaluated

Exercise performed to reduce glycogen, followed by a recovery period of $3 \mathrm{~h}$ in which there was consumption of low or high Gl meal ( $2 \mathrm{~g} / \mathrm{kg}$ of $\mathrm{CHO})$, followed by a $5 \mathrm{~km}$ bicycle course. Trials with 7-day intervals.
Brown et al Blind RCT crossed $(2013)^{31} \quad$ with cyclists of the male sex $(n=7)$ performance (time)
Glucose, insulin, FFA and TG; fat oxidation and $\mathrm{CHO}$; RER; performance (traveled time)
There was no significant difference in the variables evaluated.

RCT: randomized controlled trial; VO2: volume of oxygen consumption; VCO2: volume of carbon dioxide production; RER: respiratory exchange rate; FFA: free fatty acids; TG: triglycerides, Hb: hemoglobin, Ht: hematocrit; CHO: carbohydrate; GI: glycemic index; TNF- $\alpha$ : TNF-alpha; BHB: $\beta$-hydroxybutyrate.

and in both, the same was higher in the low GI intervention group (high $\mathrm{x}$ low GI: $101.4 \pm 5.2$ minutes $\mathrm{x} 108.8 \pm 4.1$ minutes; $48.9 \pm 10$ minutes $\times 67.4 \pm 8.4$ minutes, $P<0.05$, respectively). In addition to these four studies, another one $e^{21}$ observed that the low GI group had greater power in the final minutes of sprinting ( $4.6 \%$ increase); however, the authors affirmed that the shortest execution time of the exercise with this intervention is probable (difference of 1.03 minutes), considering the non-statistical finding. Contrary to these, another study ${ }^{18}$ evaluated time to exhaustion and observed that the duration of the test was $15 \%$ higher in the high GI group after a 4 -hour recovery period $(86.6 \pm 10.7$ minutes vs. 
selected studies, and significant differences in favor of low GI intervention were found in only four studies. ${ }^{16,17,21,22}$ This intervention obtained higher glycemia at different moments of physical exercise, being: the first 30 minutes of exercise, which used $2 \mathrm{~g}$ of $\mathrm{CHO} / \mathrm{kg}$ of weight in the pre-exercise meal ${ }^{16}$; at the end of the exercise, which used $1 \mathrm{~g}$ and $10 \mathrm{~g}$ of $\mathrm{CHO} / \mathrm{kg}$ in the pre-exercise meal ${ }^{17,21}$; and a study ${ }^{22}$ in which the intervention was before and during a recovery period, using 1.5 and $2.0 \mathrm{~g}$ of $\mathrm{CHO} / \mathrm{kg}$, respectively.

Glycerol concentrations were measured in four studies, ${ }^{16,18,23,24}$ and 2 of them reported a significant difference during exercise or at the time of exhaustion. In one study ${ }^{16}$ the glycerol levels were significantly higher in the low GI group during exercise $(20 \mu \mathrm{mol} / \mathrm{L} \times 300 \mu \mathrm{mol} / \mathrm{L})$. At the time of exhaustion, one study ${ }^{18}$ showed higher glycerol levels in the high GI group $(0.08 \mathrm{mmol} / \mathrm{L}$ x $0.45 \mathrm{mmol} / \mathrm{L})$. In 10 studies, the levels of FFA were measured, and significant differences at elevated levels during exercise, at the time of exhaustion, and at the end of the exercise were found in only three of them; one of them ${ }^{16}$ observed higher concentrations of FFA in the low GI group during all exercise, another one ${ }^{18}$ obtained the same significant result at the time of exhaustion in the high GI group, and the third study, ${ }^{22}$ which applied intervention in men and women, found higher levels of FFA only in the final sprints and only in the women of the high GI group (0.1 $\mathrm{mmol} / \mathrm{L}$ x $1.1 \mathrm{mmol} / \mathrm{L} ; P<0.05)$.

Thirteen articles analyzed lactate levels, and 2 found significant differences. These studies ${ }^{20,22}$ found higher lactate levels in the high GI group, but at different times: near the end of exercise in one of them, ${ }^{22}$ and during the whole exercise in another. ${ }^{20}$ The intake of $\mathrm{CHO}$ prior to exercise in these studies was of $1.5 \mathrm{~g} / \mathrm{kg}$ and $2.5 \mathrm{~g} / \mathrm{kg}$, respectively.

The inflammation parameters IL-2, IL- 6 , and TNF- $\alpha$ were measured in only one study, ${ }^{25}$ which reported that IL-6 levels increased more than 100 times after exercise in all intervention groups $(0.70 \mathrm{pg} / \mathrm{ml} \times 82.09 \mathrm{pg} / \mathrm{mL})$; however, these values returned more rapidly to baseline in the low GI meal group compared to the control alone, and did not replicate the same effects in the other 2 cytokines. The same study was the only one to find a significant difference regarding cortisol, these results being similar to those of IL-6.

In relation to the other biochemical parameters (insulin, $\mathrm{TG}, \mathrm{Hb}, \mathrm{Ht}$, sodium, potassium, osmolarity, $\mathrm{BHB}$ and $\beta$-endorphin), no significant differences were found during or after sports practice with any of the interventions.

Oxidation of $\mathrm{CHO}$ and Fat, Respiratory Exchange Rate, Volume of Oxygen Consumption, Carbon Dioxide Output, and Energy Expenditure

The oxidation of $\mathrm{CHO}$ and fats was measured in 14 studies, and four found significant differences. ${ }^{16,17,21,22}$ Fat oxidation was higher in the low GI group in 2 studies $^{16,21}$ (low GI $x$ high GI: $24.9 \pm 2.8 \mathrm{~g} \times 10.5 \pm 1.3 \mathrm{~g}$ and the other one without numerical data) which used $2 \mathrm{~g}$ and $10 \mathrm{~g}$ of $\mathrm{CHO} / \mathrm{kg}$ of weight, respectively. Moreover, fat oxidation was lower in the low GI group, ${ }^{19}$ which used $1 \mathrm{~g}$ of $\mathrm{CHO} / \mathrm{kg}$ of weight. In contrast, another study ${ }^{22}$ found greater $\mathrm{CHO}$ oxidation in the high GI group and no significant difference between the groups in fat oxidation; the meals offered contained $1.5 \mathrm{~g} \mathrm{CHO} / \mathrm{kg}$ of weight. The respiratory exchange ratio (RER) was measured in 11 studies, and a difference was found in two of them. ${ }^{16,17}$ One of these studies ${ }^{19}$ found a higher RER value in the low GI group $(0.94 \pm 0.03 \times 0.90 \pm 0.03)$. The other study ${ }^{16}$ found the same result for the high GI group $(0.98 \pm 0.01 \times 0.94 \pm 0.01)$ during exercise.

The volume of oxygen consumption $\left(\mathrm{VO}_{2}\right)$ was evaluated in 12 studies, but none found differences between the groups. The production of carbon dioxide $\left(\mathrm{VCO}_{2}\right)$ was analyzed in nine studies and the energy expenditure in three. Likewise, none of them found significant differences in these parameters.

\section{Body Composition (Body Mass and Fat)}

A total of three articles ${ }^{16,18,20}$ looked for changes in the body composition of the participants of each research; however, none found significant differences.

Perception of Effort, Thirst and/or Appetite, Abdominal Discomfort, Fullness, Gastrointestinal Symptoms The perception of effort was evaluated in 11 articles, and three of them ${ }^{16,18,23}$ also evaluated thirst. No significant results were found. Likewise, gastrointestinal symptoms and/or abdominal discomfort and/or fullness were analyzed in five studies $^{16,18,22-24}$ and no significant results were found in any of them.

\section{Discussion}

Less than half of the studies evaluated showed differences in relation to sports performance using pre-exercise meals of high or low GI, and low GI interventions were more advantageous on this outcome. Only one study ${ }^{18}$ found a better performance after a high GI meal intake, in which the protocol used was a constant run of 90 minutes followed by a recovery time of 4 hours, then running to exhaustion. In this case, a glycogen depletion protocol was applied in which the intervention ( $1.5 \mathrm{~g} \mathrm{CHO} / \mathrm{kg}$ of body weight) was performed at the time of recovery between the two exercises, where the use of high GI CHO could theoretically accelerate the resynthesis of glycogen. ${ }^{32}$ The other four studies ${ }^{16,17,19,20}$ observed better performances after consumption of a low GI pre-exercise meal, and the type of exercise performed was predominantly cycling. In these studies, the authors believed that the improvement in performance was due to a more stable glycemic response promoted by the low GI meal, preserving glycogen for muscle work.

Although all studies evaluated and compared blood glucose levels between intervention groups, of the 4 studies ${ }^{16,17,21,22}$ that found a significant difference in this parameter, only two ${ }^{16,17}$ observed improvement in performance. These four studies verified a higher glycemia in the low GI group at the initial ${ }^{16}$ or final ${ }^{17,21,22}$ moments of exercise. Despite this, the increase in glycemia did not promote a significant increase in insulinemia between groups. This result was already expected, once the levels of insulin did not rise during exercise, even with $\mathrm{CHO}$ reposition. ${ }^{16,33-35}$

The levels of glycerol and FFA presented contradictory results in studies that found differences in these 
parameters. ${ }^{16,18,22}$ In theory, low GI meals promote a gradual release of glucose into the bloodstream and do not stimulate significant increases in insulinemia, optimizing the release and oxidation of lipids. ${ }^{9}$ However, only one ${ }^{16}$ of the 16 studies included in this review fully corroborated this inference, not allowing further conclusions.

Regarding lactate levels, it was possible to observe increased values after a high GI meal during or at the end of exercise in only two ${ }^{20,22}$ of the 13 studies that evaluated this variable. Muscle acidosis through lactate production has long been considered one of the main limiting physiological events of sports performance. ${ }^{36}$ However, some findings have contributed to the change in the lactate paradigm, especially regarding its relation to intramuscular acidosis, indicating that acidosis associated with exercise is induced by the increase in $\mathrm{H}^{+}$ions derived from the hydrolysis of ATP $($ATP $+\mathrm{H} 2 \mathrm{O} \Leftarrow \Rightarrow$ $\mathrm{ADP}+\mathrm{Pi}+\mathrm{H}^{+}$) and not the lactate itself. It is proposed that the lactate produced during exercise acts as a regulator of the accumulation of $\mathrm{H}^{+}$ions in the intramuscular space, because it is easily transported to the interstitial space or to the blood, captured by other cells, and metabolized in the Krebs cycle or in the gluconeogenic pathway. ${ }^{37}$ Thus, the results found on the effects of GI in the pre-exercise meal on lactate levels seem irrelevant.

Most of the studies evaluated presented mixed and contradictory results in relation to the variables measured, and several of them did not report any change after GI manipulation to insulin, $\mathrm{TG}, \mathrm{Hb}, \mathrm{Ht}$, sodium, potassium, osmolarity, $\mathrm{BHB}, \beta$-endorphin, $\mathrm{VO}_{2}, \mathrm{VCO}_{2}$, inflammatory parameters, cortisol, energy expenditure, body composition, perception of effort, thirst or appetite and gastrointestinal symptoms. Regardless of this, psychological and individual tolerance issues can also influence performance, although they are not within the scope of this review.

The number of studies that found some difference in performance remains very low compared to the total number of works evaluated. It is important to note that the heterogeneity of the results related to sports performance may be due to differences in the protocol of $\mathrm{CHO}$ use or the type, duration, and intensity of the exercises performed in them. Nevertheless, it can be seen that the amount of $\mathrm{CHO}$ consumed in most of the studies corroborates the recent recommendation of the American College of Sports Medicine ${ }^{1}$ that suggests the intake of 1-4 g of $\mathrm{CHO}$ in the pre-exercise meal. Figure 2 illustrates the heterogeneity of the findings in relation to the parameters that presented a statistically significant difference between the intervention groups.

The following limitations of the studies in this review can be noted: (a) variations in the time interval between the meal and the exercise (45 minutes and 3 hours); (b) the difference in physical fitness of the evaluated individuals (physically active individuals x professional athletes); (c) the heterogeneity of the protocols of exercise; and (d) the reduced sample size in each clinical trial. Most of the studies evaluated GI against an acute intervention (1 meal), which may be limiting to produce more pronounced effects on performance. Likewise, the time of application and monitoring of dietary interventions was extremely short for a consistent analysis of the intervention. In this sense, a recent meta-analysis ${ }^{38}$ found limitations in the results evaluated, such as the low number of studies with a test protocol for each exercise; the lack of statistical power in the studies in relation to the time of the pre-exercise meal, glycemic load, and meal composition; and the physical conditions of the participants, limiting the ability to evaluate the influence of these factors on the results of the studies. Another important point to be remarked is that the applicability of the meals in the studies evaluated in this review does not necessarily reflect the reality of the feeding of high-level athletes.

\section{Conclusions}

Judging from the wide range of controversial results or nonexistent differences in the currently available literature and considering the other limitations previously described, the GI of the pre-exercise meal does not seem to influence sports performance.

\section{Authors' Contributions}

LCF and GLM were involved in the database search, extracting data, the early drafting and the revision of the manuscript; CGS acted as advisor in all stages of the research, contributed to the conception and design of the study, and aided in writing and revising the manuscript.

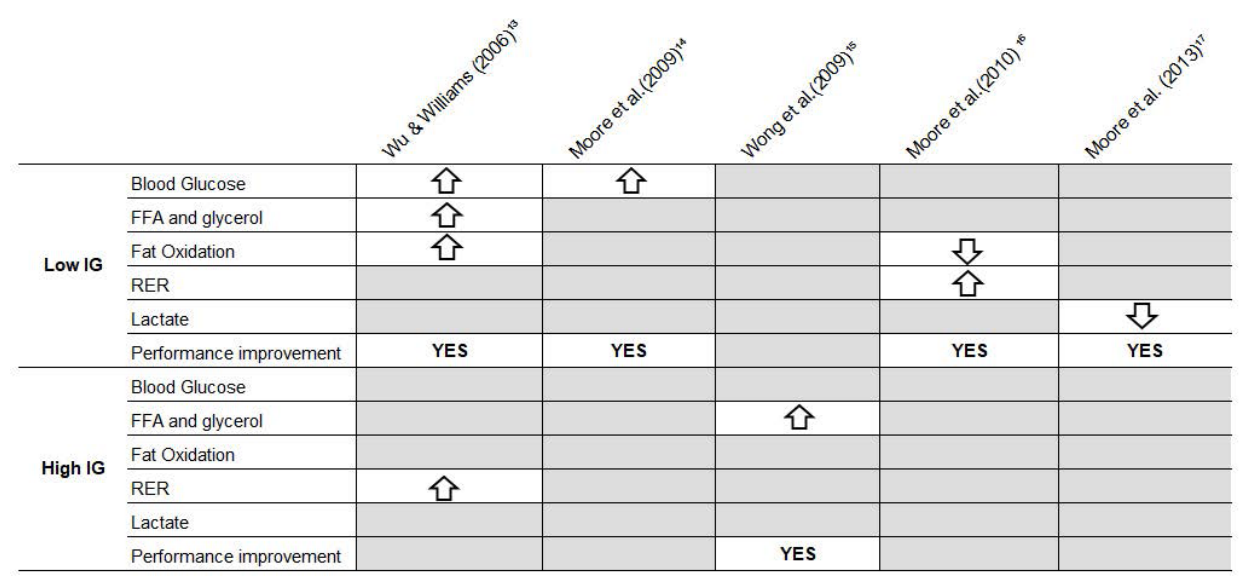

Figure 2. Relevant Findings on Performance Improvement Related to the Intervention Groups 


\section{Conflict of Interest Disclosures}

The authors declare that the present work has no conflicts of interest and did not receive any type of financing.

\section{References}

1. Thomas DT, Erdman KA, Burke LM. American College of Sports Medicine Joint Position Statement. Nutrition and Athletic Performance. Med Sci Sports Exerc. 2016;48(3):543-568. doi:10.1249/mss.0000000000000852.

2. Burke LM, Hawley JA, Wong SH, Jeukendrup AE. Carbohydrates for training and competition. J Sports Sci. 2011;29 Suppl 1:S17-27. doi:10.1080/02640414.2011.585473.

3. Stellingwerff T, Cox GR. Systematic review: Carbohydrate supplementation on exercise performance or capacity of varying durations. Appl Physiol Nutr Metab. 2014;39(9):998-1011. doi:10.1139/apnm-2014-0027.

4. Konig D, Theis S, Kozianowski G, Berg A. Postprandial substrate use in overweight subjects with the metabolic syndrome after isomaltulose (Palatinose) ingestion. Nutrition. 2012;28(6):651656. doi:10.1016/j.nut.2011.09.019.

5. van Can JGP, van Loon LJC, Brouns F, Blaak EE. Reduced glycaemic and insulinaemic responses following trehalose and isomaltulose ingestion: implications for postprandial substrate use in impaired glucose-tolerant subjects. Br J Nutr. 2012;108(7):1210-1217. doi:10.1017/S0007114511006714.

6. Oosthuyse T, Carstens M, Millen AM. Ingesting Isomaltulose Versus Fructose-Maltodextrin During Prolonged Moderate-Heavy Exercise Increases Fat Oxidation but Impairs Gastrointestinal Comfort and Cycling Performance. Int J Sport Nutr Exerc Metab. 2015;25(5):427-438. doi:10.1123/ijsnem.2014-0178.

7. Ormsbee MJ, Bach CW, Baur DA. Pre-exercise nutrition: the role of macronutrients, modified starches and supplements on metabolism and endurance performance. Nutrients. 2014;6(5):1782-1808. doi:10.3390/nu6051782.

8. Febbraio MA, Keenan J, Angus DJ, Campbell SE, Garnham AP. Preexercise carbohydrate ingestion, glucose kinetics, and muscle glycogen use: effect of the glycemic index. J Appl Physiol (1985). 2000;89(5):1845-1851. doi:10.1152/jappl.2000.89.5.1845.

9. Achten J, Jeukendrup AE. The effect of pre-exercise carbohydrate feedings on the intensity that elicits maximal fat oxidation. J Sports Sci. 2003;21(12):1017-1024. doi:10.1080/026404103100016414 03.

10. Naderi A, de Oliveira EP, Ziegenfuss TN, Willems MT. Timing, Optimal Dose and Intake Duration of Dietary Supplements with Evidence-Based Use in Sports Nutrition. J Exerc Nutrition Biochem. 2016;20(4):1-12. doi:10.20463/jenb.2016.0031.

11. dos Santos Fontan J, Amadio MB. Use of carbohydrate before physical activity as ergogenic aid: a systematic review. [O uso do carboidrato antes da atividade física como recurso ergogênico: revisão sistemática]. Rev Bras Med Esporte. 2015;21(2):153-157. doi:10.1590/1517-86922015210201933.

12. Donaldson CM, Perry TL, Rose MC. Glycemic index and endurance performance. Int J Sport Nutr Exerc Metab. 2010;20(2):154-165. doi:10.1123/ijsnem.20.2.154.

13. O'Reilly J, Wong SH, Chen Y. Glycaemic index, glycaemic load and exercise performance. Sports Med. 2010;40(1):27-39. doi:10.2165/11319660-000000000-00000.

14. Higgins JPT GS. Cochrane Handbook for Systematic Reviews of Interventions. Version 5.1.0 [updated March 2011]. http:// handbook.cochrane.org. Published 2011.

15. Liberati A, Altman DG, Tetzlaff J, et al. The PRISMA statement for reporting systematic reviews and meta-analyses of studies that evaluate health care interventions: explanation and elaboration. PLoS Med. 2009;6(7):e1000100. doi:10.1371/journal. pmed. 1000100

16. Wu CL, Williams C. A low glycemic index meal before exercise improves endurance running capacity in men. Int J Sport Nutr
Exerc Metab. 2006;16(5):510-527. doi:10.1123/ijsnem.16.5.510.

17. Moore LJ, Midgley AW, Thomas G, Thurlow S, McNaughton LR. The effects of low- and high-glycemic index meals on time trial performance. Int J Sports Physiol Perform. 2009;4(3):331-344. doi:10.1123/ijspp.4.3.331

18. Wong SH, Chen YJ, Fung WM, Morris JG. Effect of glycemic index meals on recovery and subsequent endurance capacity. Int J Sports Med. 2009;30(12):898-905. doi:10.1055/s-0029-1237710.

19. Moore LJ, Midgley AW, Thurlow S, Thomas G, Mc Naughton LR. Effect of the glycaemic index of a pre-exercise meal on metabolism and cycling time trial performance. J Sci Med Sport. 2010;13(1):182-188. doi:10.1016/j.jsams.2008.11.006.

20. Moore L, Szpalek HM, McNaughton LR. Preexercise high and low glycemic index meals and cycling performance in untrained females: randomized, cross-over trial of efficacy. Res Sports Med. 2013;21(1):24-36. doi:10.1080/15438627.2012.738442.

21. Konig D, Zdzieblik D, Holz A, Theis S, Gollhofer A. Substrate Utilization and Cycling Performance Following Palatinose Ingestion: A Randomized, Double-Blind, Controlled Trial. Nutrients. 2016;8(7). doi:10.3390/nu8070390.

22. Bennett CB, Chilibeck PD, Barss T, Vatanparast H, Vandenberg A, Zello GA. Metabolism and performance during extended highintensity intermittent exercise after consumption of low- and highglycaemic index pre-exercise meals. Br J Nutr. 2012;108 Suppl 1:S81-90. doi:10.1017/s0007114512000840.

23. Wong SH, Chan OW, Chen YJ, Hu HL, Lam CW, Chung PK. Effect of preexercise glycemic-index meal on running when $\mathrm{CHO}$ electrolyte solution is consumed during exercise. Int J Sport Nutr Exerc Metab. 2009;19(3):222-242. doi:10.1123/ijsnem.19.3.222.

24. Hulton AT, Gregson W, Maclaren D, Doran DA. Effects of GI meals on intermittent exercise. Int J Sports Med. 2012;33(9):756-762. doi:10.1055/s-0031-1299754.

25. Chen YJ, Wong SH, Chan CO, Wong CK, Lam CW, Siu PM. Effects of glycemic index meal and $\mathrm{CHO}$-electrolyte drink on cytokine response and run performance in endurance athletes. J Sci Med Sport. 2009;12(6):697-703. doi:10.1016/j.jsams.2008.05.007.

26. Kern M, Heslin CJ, Rezende RS. Metabolic and performance effects of raisins versus sports gel as pre-exercise feedings in cyclists. J Strength Cond Res. 2007;21(4):1204-1207. doi:10.1519/r-21226.1.

27. Little JP, Chilibeck PD, Ciona D, Vandenberg A, Zello GA. The effects of low- and high-glycemic index foods on high-intensity intermittent exercise. Int J Sports Physiol Perform. 2009;4(3):367380. doi:10.1123/ijspp.4.3.367.

28. Little JP, Chilibeck PD, Ciona D, et al. Effect of low- and highglycemic-index meals on metabolism and performance during high-intensity, intermittent exercise. Int J Sport Nutr Exerc Metab. 2010;20(6):447-456. doi:10.1123/ijsnem.20.6.447.

29. Jamurtas AZ, Tofas T, Fatouros I, et al. The effects of low and high glycemic index foods on exercise performance and beta-endorphin responses. J Int Soc Sports Nutr. 2011;8:15. doi:10.1186/15502783-8-15.

30. Moore LJ, Midgley A, Vince R, McNaughton LR. The effects of low and high glycemic index 24-h recovery diets on cycling time trial performance. J Sports Med Phys Fitness. 2011;51(2):233-240.

31. Brown LJ, Midgley AW, Vince RV, Madden LA, McNaughton LR. High versus low glycemic index 3 -h recovery diets following glycogen-depleting exercise has no effect on subsequent $5-\mathrm{km}$ cycling time trial performance. J Sci Med Sport. 2013;16(5):450454. doi:10.1016/j.jsams.2012.10.006.

32. Stevenson E, Williams C, McComb G, Oram C. Improved recovery from prolonged exercise following the consumption of low glycemic index carbohydrate meals. Int J Sport Nutr Exerc Metab. 2005;15(4):333-349. doi:10.1123/ijsnem.15.4.333.

33. McArdle WD, Katch FI, Katch VL. Fisiologia do Exercício Nutrição, Energia e Desempenho Humano. 8th ed. Guanabara Koogan; 2016.

34. Lima-Silva AE, Fernandes TC, De-Oliveira FR, Nakamura FY, da 
Silva Gevaerd M. Muscle glycogen metabolism during exercise: mechanism of regulation. Rev Nutr. 2007;20(4):417-429. doi:10.1590/S1415-52732007000400009.

35. da Silva AL, Miranda GDF, Liberali R. A influência dos carboidratos antes, durante e após-treinos de alta intensidade. Rev Bras Nutr Esportiva. 2008;2(10):211-224.

36. de Moraes Bertuzzi RC, Lima-Silva AE, Abad CC, de Oliveira Pires F. Lactate metabolism: a review on bioenergetics and muscle fatigue. [Metabolismo do lactato: uma revisão sobre a bioenergética e a fadiga muscular]. Rev Bras Cineantropom Desempenho Hum. 2009;11(2):226-234. doi:10.5007/1980-0037.2009v11n2p226.

37. Nalbandian M, Takeda M. Lactate as a Signaling Molecule That Regulates Exercise-Induced Adaptations. Biology (Basel). 2016;5(4). doi:10.3390/biology5040038.

38. Burdon CA, Spronk I, Cheng HL, O'Connor HT. Effect of glycemic index of a pre-exercise meal on endurance exercise performance: A systematic review and meta-analysis. Sports Med. 2017;47(6):1087-1101. doi:10.1007/s40279-016-0632-8. 